Brazilian Journal

of Chemical

Engineering

\title{
ASSESSMENT OF POLYHYDROXYALKANOATE SYNTHESIS IN SUBMERGED CULTIVATION OF Cupriavidus necator AND Burkholderia cepacia STRAINS USING SOYBEAN AS SUBSTRATE
}

\author{
Plínio R. Rodrigues ${ }^{1 *}$, Jéssica M. N. Nunes ${ }^{1}$, Luciana N. Lordelo ${ }^{1}$ and Janice I. Druzian ${ }^{1}$ \\ ${ }^{1}$ Universidade Federal da Bahia, Programa de Pós-Graduação em Engenharia Química, Salvador/BA, Brasil. E-mail: plinioeng@hotmail.com, \\ ORCID: 0000-0002-6652-5470
}

(Submitted: May 19, 2017 ; Revised: February 26, 2018 ; Accepted: March 6, 2018)

\begin{abstract}
Polyhydroxyalkanoates (PHA) are biocompatible and biodegradable polyesters produced by prokaryotic microbes for energy storage and carbon reserve. These polymers are an option to diminish the massive impact caused by inadequate disposal of synthetic plastics. In this study, evaluation and characterization of PHA produced by Cupriavidus necator (IPT 026 and IPT 027) and Burkholderia cepacia (IPT 119 and IPT 400), using soybean as substrate, were carried out (soybean $15 \mathrm{~g} \mathrm{~L}^{-1}, \mathrm{pH} 7.0,150 \mathrm{rpm}, 72$ hours). The highest polymer production was achieved using IPT $027\left(0.84 \pm 0.07 \mathrm{~g} \mathrm{~L}^{-1}\right)$. All PHA produced showed the characteristic bands of polyester functional groups in the FTIR spectra. Polymers synthesized by Cupriavidus necator exhibited initial temperatures of degradation superior to $300 \mathrm{oC}$ and higher molecular weights than the ones produced by Burkholderia cepacia, which in turn, exhibited lower crystallinity (inferior to 30\%), revealing high influence of the microorganism strain on PHA properties and production.

Keywords: Soybean; Biosynthesis; Biopolyester; Characterization.
\end{abstract}

\section{INTRODUCTION}

Petroleum based plastics are widely used in daily life due to their low cost, versatility, ease of processing and resistance, and their market share is gigantic and very profitable (Berto et al., 2017). However, the durability associated with the characteristics of nonbiodegradability of these polymers compromise the world sustainability, since their accumulation in the environment entails great damages to the ecosystem.

As a result, the replacement of synthetic materials by biodegradable ones, at competitive costs, is an emerging need that must be fulfilled. A promising alternative to this demand is the production of bacterial biopolymers, especially the group formed by polyhydroxyalkanoates (PHA), since the referred materials can replace conventional thermoplastics
(Ray et al., 2016; Faccin et al., 2013; Kourmentza et al. 2017; Koller et al., 2017).

PHA are a family of biocompatible and biodegradable polyesters with diverse structures and properties. The presence of 150 monomeric compositions has been reported, which grants them a broad set of applications. They can be intracellularly produced by numerous bacteria, being stored as an energy source, and also can be industrially biosynthesized from renewable raw materials, such as glucose and sucrose. However, these sugars represent a high cost in the production chain and therefore the use of cheaper carbon sources has been largely investigated and encouraged (HE et al.; 1999; Wu et al., 2000; Chen et al., 2016).

Yet, most studies are focused on the use of substrates predominantly constituted by carbohydrates (Wang et

\footnotetext{
* Corresponding author: Plínio R. Rodrigues - E-mail: plinioeng@hotmail.com
} 
al., 2013; Carvalho et al., 2014; Ribeiro et al., 2016) or lipids (Altaee et al., 2016; Riedel et al., 2015; Morais et al., 2014; Shahzad et al., 2017), the use of complex substrates containing high fractions of both nutrients is an approach scarcely investigated in PHA synthesis (Koller et al., 2017).

Soybean plant (Glycine max) is one of the world's most economically important crops, cultured for the production of oleaginous grains used as feedstock in the manufacture of numerous products. This herbaceous vegetal has experienced the largest percentage increase in planted area since 1970, compared to any other major crop (Hartman et al., 2011; Figueiredo, 2016). United States and Brazil are, respectively, the first and second largest soybean producers in the world. In Brazil, world leader in productivity $(\mathrm{kg} / \mathrm{ha})$, the cost of production fell to about US-\$ 6.30 per $60 \mathrm{~kg} / \mathrm{bag}$, which is around half the cost practiced in the United States (Figueiredo, 2016).

In this context, this study aims to evaluate and characterize PHA productions using soybean, largely available in Brazil, as an alternative and complex substrate for the submerged cultivation of the bacterial strains Cupriavidus necator IPT 026 and 027, and Burkholderia cepacia IPT 119 and 400. Since the use of low cost alternative substrates can enhance PHA production's economic sustainability, this adds value to the raw material.

\section{MATERIALS AND METHODS}

\section{Bacterial strains}

Cupriavidus necator IPT 026 and IPT 027, and Burkholderia cepacia IPT 400 and ITP 119 were supplied by the Institute of Technological Research (IPT), in São Paulo, Brazil. The bacteria were grown at $33^{\circ} \mathrm{C}$ in nutrient broth, maintained on nutrient agar (NA) at $4^{\circ} \mathrm{C}$ and subcultured every 15 days.

\section{Main carbon source}

Soybean was acquired in the trade market of Salvador-BA, Brazil, milled to a particle size of 20-40 mesh and stored at $4{ }^{\circ} \mathrm{C}$ for preservation.

\section{Chemical composition of carbon source}

The soybean chemical composition was evaluated in triplicate, total lipids were analyzed according to Bligh and Dyer (1959), moisture, crude ash, and crude protein were determined by analysis methods published by the Association of Official Analytical Chemists (AOAC, 1997). Carbohydrate content was calculated by percent mass difference, according to Eq (1).

Carbohydrate $\%=100-($ Ash $\%+$ Protein $\%+$ Moisture $\%+$ Lipid $\%)$
Total carbon (C) content was determined according to Nelson and Sommers (1982) and total nitrogen (N) content was determined by the Kjehldal method (AOAC, 1997).

The fatty acid profile was determined by a capillary column gas chromatographic method according to Joseph and Ackman (1992) and Nascimento et al. (2013). The separation of the methyl esters in the fatty acids was performed using gas chromatography (Varian 3800) with a flame ionization detector (GCFID) and a fused silica gas chromatography capillary column EliteWAX $(30 \mathrm{~m} \times 0.32 \mathrm{~mm} \times 0.25 \mu \mathrm{m})$ : split injection $(1: 100)$, injector temperature at $250^{\circ} \mathrm{C}$, detector temperature at $280^{\circ} \mathrm{C}$, column temperature maintained at $150^{\circ} \mathrm{C}$ for 16 minutes and programmed to increase $2^{\circ} \mathrm{C}$ per minute until $180^{\circ} \mathrm{C}$, remaining at this temperature for 25 minutes and then programmed to increase $5^{\circ} \mathrm{C}$ per minute until $210^{\circ} \mathrm{C}$, remaining at this last temperature for 25 minutes.

The quantification of fatty acids, expressed in milligrams per $100 \mathrm{~g}$ sample, was executed by the addition of an internal standard (C23:0 Sigma ${ }^{\circledR}$, USA) according to Joseph and Ackman (1992) and calculated using Eq. (2).

Concentration $(\mathrm{mg} / 100 \mathrm{~g}$ sample $)=\frac{\mathrm{A}_{\mathrm{FA}} \times \mathrm{M}_{\mathrm{SI}} \times \mathrm{F} \times \mathrm{C}_{\mathrm{TL}}}{\mathrm{A}_{\mathrm{IS}} \times \mathrm{M} \times \mathrm{F}_{\mathrm{FA}}} \cdot 1000$

where $\mathrm{A}_{\mathrm{FA}}=$ area of fatty acid methyl ester peak in the chromatogram of the sample; $\mathrm{M}_{\mathrm{IS}}=$ weight (in milligrams) of the internal standard added to the sample; $\mathrm{F}=$ correction factor of fatty acid methyl ester to fatty acid; $\mathrm{C}_{\mathrm{TL}}=$ percentage composition of total lipids from the sample; $\mathrm{A}_{\mathrm{IS}}=$ area of internal standard fatty acid methyl ester peak in the chromatogram of the sample; $\mathrm{M}=$ sample mass (in milligrams); $\mathrm{F}_{\mathrm{FA}}=$ correction factor response of each fatty acid methyl ester ionization detector, relative to $\mathrm{C} 23: 0$.

\section{PHA production}

Culture media

The bacteria were stored at $4^{\circ} \mathrm{C}$ in nutrient agar (NA) composed of $5.0 \mathrm{~g} \mathrm{~L}^{-1}$ meat peptone, $3.0 \mathrm{~g} \mathrm{~L}^{-1}$ beef extract, and $3.75 \mathrm{~g} \mathrm{~L}^{-1}$ agar. Inoculation was performed in nutrient broth (NB), composed of 5.0 $\mathrm{g} \mathrm{L}^{-1}$ bacteriological peptone, $3.0 \mathrm{~g} \mathrm{~L}^{-1}$ beef extract, and distilled water, over a period of $24 \mathrm{~h}$. PHA was produced by a two stage cultivation process, as described by Wang et al. (2013) and Campos et al. (2014).

Mineral media were used as the first culture (FC), with no nitrogen limitation, and as the second culture (SC), with nitrogen limitation. Both FC and SC were composed of nitrilotriacetic acid $\left(0.1 \mathrm{~g} \mathrm{~L}^{-1}\right)$, ferrous ammonium citrate $\left(0.04 \mathrm{~g} \mathrm{~L}^{-1}\right), \mathrm{MgSO}_{4} \cdot 7 \mathrm{H}_{2} \mathrm{O}(0.1 \mathrm{~g}$ $\left.\mathrm{L}^{-1}\right), \mathrm{CaCl}_{2} \cdot 2 \mathrm{H}_{2} \mathrm{O}\left(0.004 \mathrm{~g} \mathrm{~L}^{-1}\right),\left(\mathrm{NH}_{4}\right)_{2} \mathrm{SO}_{4}$ (nitrogen 
source; $0.625 \mathrm{~g} \mathrm{~L}^{-1}$ in $\mathrm{FC}$ and $0.361 \mathrm{~g} \mathrm{~L}^{-1}$ in $\mathrm{SC}$ ); $\mathrm{Na}_{2} \mathrm{HPO}_{4} \cdot 12 \mathrm{H}_{2} \mathrm{O}\left(1.6 \mathrm{~g} \mathrm{~L}^{-1}\right), \mathrm{KH}_{2} \mathrm{PO}_{4}\left(1.6 \mathrm{~g} \mathrm{~L}^{-1}\right)$ and the main carbon source (whole ground soybean at 15 $\left.\mathrm{g} \mathrm{L}^{-1}\right)$. Media $\mathrm{pH}$ was adjusted to 7.0 with $\mathrm{NaOH}(10$ $\left.\mathrm{mol} \mathrm{L}{ }^{-1}\right)$ or $\mathrm{HCl}\left(10 \mathrm{~mol} \mathrm{~L}^{-1}\right)$.

\section{Shake flask cultivation}

A volume of $10 \mu \mathrm{L}$ of the microorganisms studied were separately inoculated into $50 \mathrm{~mL}$ of NB medium in Erlenmeyer flasks, and incubated at $30^{\circ} \mathrm{C}, 150 \mathrm{rpm}$ and $24 \mathrm{~h}$, in rotary orbital shaker (Tecnal, model TE-424). Subsequently, $10 \% \mathrm{v} / \mathrm{v}$ of inoculum was transferred to Erlenmeyer flasks containing $80 \mathrm{~mL}$ of $\mathrm{FC}$ medium, followed by further incubation at $35^{\circ} \mathrm{C}, 150 \mathrm{rpm}$ for $24 \mathrm{~h}$. Finally, $10 \% \mathrm{v} / \mathrm{v}$ of FC was transferred to $80 \mathrm{~mL}$ of SC and incubated at $35^{\circ} \mathrm{C}, 180 \mathrm{rpm}$ and $72 \mathrm{~h}$. All media used in the bacterial cultivations were sterilized at $121^{\circ} \mathrm{C}$ for 20 minutes in autoclave.

\section{PHA recovery and separation}

Cell cultures were harvested by centrifugation at $15,700 \times \mathrm{g}$ for $30 \mathrm{~min}$ at $5^{\circ} \mathrm{C}$ (HITACHI, model CR $22 \mathrm{G}$ ), washed twice with distilled water, transferred into round bottom flasks $(50 \mathrm{~mL})$, and frozen at $-8^{\circ} \mathrm{C}$ for subsequent lyophilization (LIOBRAS model L101) at $-42^{\circ} \mathrm{C}$ for $24 \mathrm{~h}$. PHA extraction from the freeze-dried cells was performed using chloroform at $60^{\circ} \mathrm{C}$ for $2 \mathrm{~h}$ with vigorous agitation on a magnetic stirrer plate with heating (model IKAHS 7), following the proportion of $0.5 \mathrm{~g}$ of cells per $50 \mathrm{~mL}$ of solvent (Campos et al., 2014). Subsequently, the solution (cells and chloroform) was filtered and stored in preweighed plates for $24 \mathrm{~h}$ to allow complete solvent evaporation, resulting in the recovery of PHA films. Cell dry mass (CDM) and PHA production (obtained after extraction) were calculated using a gravimetric method and expressed in $\mathrm{g} \mathrm{L}^{-1}$.

\section{PHA characterization}

Fourier transform infrared spectroscopy (FTIR)

PHA functional group characterization was determined by FTIR spectroscopy (PerkinElmer Spectrum 100, Waltham, Massachusetts, USA) between the wave numbers of $4000 \mathrm{~cm}^{-1}$ and $400 \mathrm{~cm}^{-1}$ using a single-bounce attenuated total reflection (ATR) accessory with a Zinc selenide ( $\mathrm{ZnSe}$ ) crystal.

\section{Thermal characterization}

Thermogravimetric analysis (TGA) (PerkinElmer Model Pyris 1TGA Waltham, Massachusetts, USA) was performed to determine the initial degradation temperature $\left(T_{\text {in }}\right)$ and the maximum decomposition temperature $\left(\mathrm{T}_{\text {maxdec }}\right)$. Five milligrams of PHA were placed in a platinum tray (cross-sectional area of 2.47 $\times 10^{-5} \mathrm{~m}^{2}$ ) and heated at the rate of $10^{\circ} \mathrm{C} / \mathrm{min}$ from $25^{\circ} \mathrm{C}$ to $600^{\circ} \mathrm{C}$ under a nitrogen flow rate of $40 \mathrm{~mL}$ $\min ^{-1}$.
$X$-ray diffraction analysis

Crystallinity and crystal peaks of the PHA samples were measured by X-ray diffraction. The X-ray diffractograms were obtained on a SHIMADZU (XRD-6000, USA) with graphite-filtered $\mathrm{CuKa}$ radiation $(\lambda=1.5433 \AA$ ) operated at $40 \mathrm{kV}$ and $30 \mathrm{~mA}$ in the region from 5 to $80^{\circ}(2 \theta)$ at a rate of $2^{\circ} / \mathrm{min}$. The percentage of crystallinity was calculated from the diffracted intensity measured by XRD according to Vonk's method (Vonk, 1973).

\section{Determination of PHA molar mass distribution}

Molar masses, expressed by the weight-average molar mass $(\mathrm{Mw})$, the number-average molar mass $(\mathrm{Mn})$ and the polydispersity index $(\mathrm{PDI}=\mathrm{Mw} / \mathrm{Mn})$, were obtained by size-exclusion chromatography (SEC) according to Campos et al. (2014) and Ribeiro et al. (2015).

High performance liquid chromatography (HPLC, PerkinElmer 200) with an auto-sampler and refractive index detector (PerkinElmer), a column Shodex KD $807(30 \mathrm{~cm} \times 78 \mathrm{~mm} \times 5 \mu \mathrm{m})$ and an oven temperature of $35^{\circ} \mathrm{C}$ were employed for separation. The polymer samples were dissolved in chloroform to a concentration of $7 \mathrm{mg} \mathrm{mL}^{-1}$. As the mobile phase, chloroform was employed at $1 \mathrm{~mL} \mathrm{~min}^{-1}$. A standard curve was created using monodisperse polystyrene standards with a range size of $68-1,670,000 \mathrm{~g} \mathrm{~mol}^{-1}$ (Polystyrene High Mw Standards Kit Polymer Standards Service, USA).

\section{Data treatment}

Data treatment was performed using the tools available in the Statistica 8.0 software (Statsoft Inc., Tulsa). Statistical significance was calculated by Tukey's test $(\mathrm{p}<0.05)$.

\section{RESULTS AND DISCUSSION}

\section{Substrate chemical composition}

Soybean is a crop largely used as food for livestock and people, as it is an abundant source of protein and oil, and for the industrial manufacturing of diverse products. The nutritional content of the oleaginous grains is variable according to climate conditions, maturity stage, portion of the seed, and the plant variety (Genovese et al., 2006; Nwokola, 1996).

It is important to remark that although soybean is used for human consumption, the choice of a raw material for the industrial production of a specific bioproduct in a given country depends primarily on its availability and on its cost (Erickson et al., 2012). Thus in some cases, the use of edible substrates for the production of plastics or even biofuels is justified and overcomes the disputes with food production. Nevertheless, this analysis must be carried out very carefully, according to the reality of each market (Nonato et al., 2001; Dias et al., 2017). 
Table 1 presents the chemical composition determined for the soybean seed used as substrate in the study of bacterial submerged cultivation for PHA production. The values are disposed as percentage averages followed by their standard deviations. The substrate carbon:nitrogen ratio $(\mathrm{C}: \mathrm{N})$ and the fatty acids profile of the lipid portion are also shown.

It is possible to observe that the highest fractions in the grain are constituted of proteins (33.62\%), carbohydrates $(32.16 \%)$, and fats $(22.24 \%)$. These results were very similar to those reported by Silva et al. (2012) and Genovese et al. (2006).

However, Felberg et al. (2004) found a protein content fraction that is almost $10 \%$ higher than what was observed in this study. Nevertheless, it is expected that the composition of soybean may vary depending on a wide range of parameters of its cultivation.

Soybean lipid fraction was composed of $18.52 \%$ saturated fatty acids (lauric [C12:0], myristic [C14:0], palmitic [C16:0], stearic [C18:0] and arachidic [C20:0]), 22.99\% monounsaturated fatty acids (oleic [C18:1]), and $58.49 \%$ polyunsaturated fatty acids (linoleic [C18:2] and linolenic [C18:3]). Commonly, most oils originated from plants display a high percentage of unsaturated fatty acids (Nwokola, 1996). Galão et al. (2014) found similar proportions assessing the fatty acid profile of the BRS245R soybean variety.

The presence of fatty acids in the substrate offered for PHA synthesis influences polymer chain length and structure (Muhr et al., 2013a; Muhr et al., 2013b). In their study of medium supplementation for PHA production, Srivastava and Tripathi (2013) found that palmitic acid supplemented media showed the presence of short chain length polyhydroxybutyrate.

Table 1. Chemical composition of whole soybean seed.

\begin{tabular}{lclc}
\hline Composition & $\begin{array}{c}\text { Avarege } \\
(\mathbf{\%})\end{array}$ & $\begin{array}{c}\text { Fatty } \\
\text { acid }\end{array}$ & $\begin{array}{c}\text { Averege } \\
(\mathbf{\%})\end{array}$ \\
\hline Moisture & $7.72 \pm 0.08$ & $\mathrm{C} 12: 0$ & $0.07 \pm 0.02$ \\
Total ash & $4.26 \pm 0.10$ & $\mathrm{C} 14: 0$ & $0.48 \pm 0.09$ \\
Total lipid & $22.24 \pm 0.09$ & $\mathrm{C} 16: 0$ & $11.87 \pm 0.06$ \\
Crude protein & $33.62 \pm 0.12$ & $\mathrm{C} 18: 0$ & $3.63 \pm 0.01$ \\
Carbohydrates & $32.16 \pm 0.39$ & $\mathrm{C} 18: 1 \omega 9 \mathrm{c}$ & $21.53 \pm 0.05$ \\
C:N* & $9.5: 1$ & $\mathrm{C} 18: 1 \omega 9 \mathrm{t}$ & $1.46 \pm 0.03$ \\
& & $\mathrm{C} 18: 2 \omega 6 \mathrm{c}$ & $54.41 \pm 0.07$ \\
& & $\mathrm{C} 18: 3 \omega 6$ & $4.08 \pm 0.02$ \\
& & $\mathrm{C}: 20$ & $2.47 \pm 0.12$ \\
\hline
\end{tabular}

On the other hand, oleic acid and linoleic acid additions showed both saturated and unsaturated PHA of different chain lengths.

The carbon:nitrogen ratio $(\mathrm{C}: \mathrm{N})$ in the soybean is approximately 10:1, however, the nitrogen source in the substrate is composed of proteins, which are a non-readily biodegradable carbon source (Oliveira et al., 2016). Therefore, the medium was supplemented with $\left(\mathrm{NH}_{4}\right)_{2} \mathrm{SO}_{4}$ to a $\mathrm{C}: \mathrm{N}$ of approximately $62: 1$ in the fermentation medium, considering no protein consumption, given the presence of a high fraction of carbon sources readily biodegradable in the substrate. The C:N values documented in the literature for PHA production are wide, ranging from 20:1 to $144: 1$, depending on the microorganism strain used (González-García et al., 2013; Kumar et al, 2004).

The chemical content found for soybean, rich in complex nutrients, suggests that this crop has a promising potential as carbon source/substrate for microorganism cultivations, since differences in trace elements and macronutrient concentrations can alter the growth and fermentation pattern in the synthesis of a desired product (Liu, 2017).

\section{Influence of bacterial strain on PHA production}

In order to select the best biocatalyst for PHA production in submerged cultivation, the effects of different microorganisms on polymer accumulation were evaluated under the same cultivation parameters.

Table 2 shows the results obtained for PHA synthesis for each microorganism studied (ANOVA: $\mathrm{F}=221.5$; $\mathrm{p}<0.0001)$, cell dry mass (CDM) production and polymer mass percentage in CDM are also displayed. C. necator IPT 027 showed the best performance in polymer production, yielding $0.84 \mathrm{gL}^{-1}$ of polyesters in the fermentation media, followed by $C$. necator IPT 026 and B. cepacia IPT 400, which produced $0.54 \mathrm{gL}^{-1}$ and $0.53 \mathrm{gL}^{-1}$, respectively. The last two strains did not present statistical differences in performance according to Tukey's test $(\mathrm{P}<0.05)$. B. cepacia IPT 119 produced $0.44 \mathrm{~g} \mathrm{~L}^{-1}$ of polymer, an amount that is $47.62 \%$ lower than what was achieved by the best performer bacteria. On average, $C$. necator strains production was $42.27 \%$ higher than what was observed for B. cepacia. These results show the great impact caused by the choice of the microorganism in the biosynthesis process.

Table 2. PHA, CDM and PHA mass percentage in CDM in fermentation of $15 \mathrm{~g} \mathrm{~L}^{-1}$ of soybean over 72 hours of incubation, $\mathrm{pH}$ of 7.0 , and rotation of $180 \mathrm{rpm}$.

\begin{tabular}{cccc}
\hline Microorganism & PHA & CDM & \multirow{2}{*}{ PHA in DCM (\%) } \\
\cline { 2 - 4 } C. necator IPT 026 & & $\left(\mathbf{g ~ L}^{-1}\right)$ & $20.21 \pm 0.16^{\mathrm{a}}$ \\
C. necator IPT 027 & $0.54 \pm 0.014^{\mathrm{a}}$ & $2.69 \pm 0.090^{\mathrm{a}}$ & $23.66 \pm 0.93^{\mathrm{b}}$ \\
B. cepacia IPT 119 & $0.84 \pm 0.021^{\mathrm{b}}$ & $3.57 \pm 0.050^{\mathrm{b}}$ & $7.38 \pm 0.56^{\mathrm{c}}$ \\
B. cepacia IPT 400 & $0.44 \pm 0.028^{\mathrm{c}}$ & $5.93 \pm 0.080^{\mathrm{c}}$ & $10.05 \pm 0.36^{\mathrm{d}}$ \\
\hline
\end{tabular}

Averages followed by different letters, in the upper right, show differences between strains in the same column, determined by Tukey's test (P $<0.05)$. 
Regarding bacterial cellular growth, B. cepacia IPT 119 exhibited the highest production, culminating with the lowest PHA accumulation (7.38\%). All other bacteria exhibited the same trend of good cellular growth and low polymer accumulation.

In his studies, Ribeiro et al. (2015) assessed the production of PHA with $C$. necator IPT 027 using glucose as carbon source, reporting $2.41 \pm 0.10 \mathrm{~g} \mathrm{~L}^{-1}$ of polymer in the culture medium with $56.57 \pm 0.56 \%$ of cellular accumulation. This value is greatly superior to the one found using soybean as substrate with the same bacterial strain.

Possibly, this polymer production difference is partly due to the more complex composition of soybean, which would lead to a more difficult absorption of nutrients by the bacteria, different from glucose that would be more easily assimilated, given its structure.

Another point to consider is that, in addition to the carbon source, the supply of nitrogen is crucial for PHA biosynthesis and accumulation within the cell. The limitation of this nutrient generates a cellular stress that leads to energy savings in the form of PHA (Madison et al., 1999). Therefore, considering the high amount of proteins present in soybean, it is possible that the bacteria investigated might have been able to use the nitrogen present in this fraction to compensate for its limitation in the culture medium, compromising the accumulation of PHA within the cells and stimulating the growth phase.

The ratio of organic carbon available in the substrate by the nitrogen supplied in the culture medium was calculated as 62:1; however, if considered that the bacteria can access carbon and nitrogen present in the protein fraction of soybean, the carbon:nitrogen ratio decreases to approximately $9: 1$, lowering greatly nitrogen limitation in the medium.

Comparable observations were made by Ramadas et al. (2009) and Gowlda et al. (2014), who also reported good cellular growth but low PHA accumulation using carbon sources with high protein content.

Regarding the performance of different bacteria and substrates in PHA production, Pal et al. (2009) published a polymer yield ranging from 0.2 to $1.2 \mathrm{~g}$ $\mathrm{L}^{-1}$ using Bacillus thuringiensis and different synthetic media. Altaee et al. (2016) reported a PHA production of $0.54 \mathrm{~g} \mathrm{~L}^{-1}$ using Rhodococcus equi and crude palm kernel oil as substrate. This last value is similar to what was found for $C$. necator IPT 026 and B. cepacia IPT 400 , and inferior to the result achieved by $C$. necator IPT 027 in the present study.

\section{PHA Characterization}

Thermochemical characterizations were executed for all PHA produced in order to evaluate their performance and capacity to attend standards that would permit their usage and commercial escalation.
PHA's functional group characterization, presented in Figure 1, was completed by spectroscopy in the infrared spectra (FTIR), the wave number $\left(\mathrm{cm}^{-1}\right)$ associated with each band corresponds to a particular functional group present in the polymer samples. Characteristic bands related to PHA structure documented in the scientific literature were observed in all samples scanned.

The band noted at $1728 \mathrm{~cm}^{-1}$ represents the axial deformation of a $\mathrm{C}=\mathrm{O}$ carbonyl group. The presence of a carbonyl band at this wave number indicates strong presence of polyhydroxybutyrate in the material structure (Hong et al., 1999). C-H carbonhydrogen bond stretchings of $\mathrm{CH}_{3}$ and $\mathrm{CH}_{2}$ groups were identified at the wave numbers $2931 \mathrm{~cm}^{-1}$ and $2854 \mathrm{~cm}^{-1}$, respectively (Hong et al., 1999; Barud et al., 2011).

The band of the carbonyl of the ester group (CC) is observed at $972 \mathrm{~cm}^{-1}$ (Xu et al., 2002). The bands at $1048 \mathrm{~cm}^{-1}$ and $1288 \mathrm{~cm}^{-1}$ are associated correspondingly to the asymmetric and the symmetric stretching vibration of the $\mathrm{C}-\mathrm{O}-\mathrm{C}$ group ( $\mathrm{Zhu}$ et al., 2001). Wagging of $\mathrm{CH}_{3}$ is related to the wave number $1381 \mathrm{~cm}^{-1}$ (Xu et al., 2002).

PHA and soybean thermal behaviors are displayed in the thermogravimetric curves (TGA) and their associated derivatives (DTGA) in Figure 2. It is possible to observe the mass variation of the samples with the temperature increase, which is related to the loss of volatile components. Thermal degradation of all polymers produced occurred in two mass loss events, which is normally associated with the presence of impurities remaining from the extraction and separation processes (González-García et al., 2013). The thermal events can be quickly identified by the inverted peaks displayed in the DTG curves.

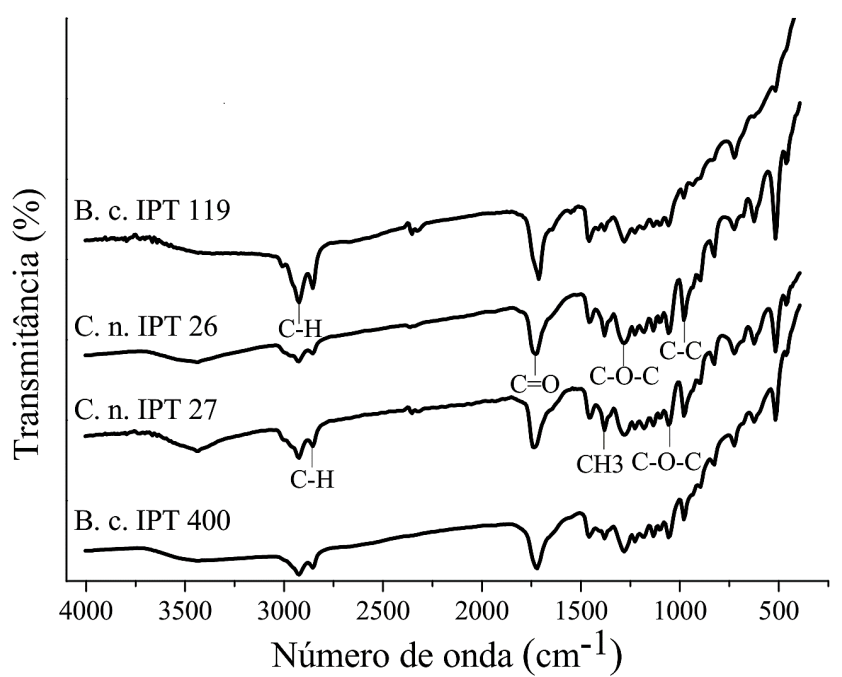

Figure 1. FTIR spectra of PHA produced by C. necator, and B. cepacia strains in submerged cultivation with soybean. 

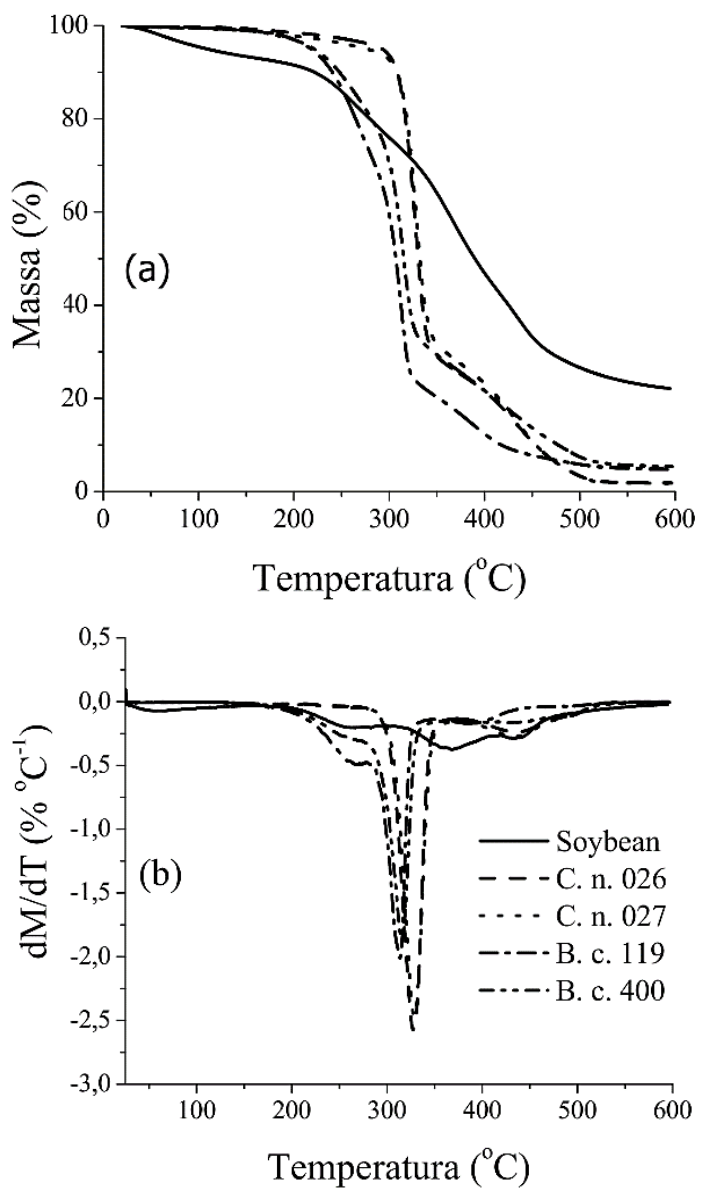

Figure 2. TGAs (a) and DTGs (b) of soybean seed and PHA produced by C.necator and B. cepacia strains in submerged cultivation.

Soybean thermal degradation occurred in three mass loss events with a total weight loss of $77.88 \%$. It is possible to observe that the first event displayed by the substrate is also seen in PHA produced by B. cepacia strains, and the third event existent in soybean is present in PHA produced by $C$. necator. The second event in soybean thermogravimetric curves was not detected in any of the polymer samples. It is possible to infer that all PHA produced presented substrate traces in its composition, remaining from the polymer extraction process.
The first thermal event seen in PHA produced by $C$. necator and the second event seen in PHA produced by $B$. cepacia were the most significant part of their mass loss behavior with temperature changes. They were different from each other and were not noted in soybean TGA/DTGA curves, being related to the characteristics of the polyesters produced.

The initial degradation temperatures $\left(\mathrm{T}_{\text {in }}\right)$ and the maximum decomposition temperatures $\left(\mathrm{T}_{\text {maxdec }}\right)$ of the thermogravimetric events obtained from the TGA/ DTGA curves for the PHA produced and for soybean are organized in Table 3.

The polymer synthetized by $C$. necator IPT 027 exhibited the best thermal stability with an initial degradation temperature of $307.03^{\circ} \mathrm{C}$, a maximum decomposition temperature of $328.41{ }^{\circ} \mathrm{C}$ and a total weight loss of $98.26 \%$ (first event). This performance was superior to that found by Ribeiro et al. (2015) in his studies of PHA production with glucose $\left(257.6^{\circ} \mathrm{C}\right)$, glycerol $\left(286.8^{\circ} \mathrm{C}\right)$ and crude glycerol $\left(267.9^{\circ} \mathrm{C}\right)$ using $C$. necator IPT 027, indicating great influence of the substrate and the biosynthesis conditions on thermal behavior. The same author also reported a $T_{\text {in }}$ of $316.7^{\circ} \mathrm{C}$ for a PHA produced by B. cepacia IPT 438 using glycerol as substrate, a result superior to those achieved by all B. cepacia strains used in this paper.

Nevertheless, the polyesters produced by B. cepacia IPT 119 and 400 displayed thermal performances superior to what was observed in the results reported by Ribeiro et al. (2016) and Ray et al. (2016) for PHA synthetized by Bacillus megaterium and Pannonibacter phragmitetus, respectively.

It is important to remark that high decomposition temperature is a crucial factor for polymer processing in industry, since the material has to be able to resist, with no structural degradation, the required temperatures for extrusion and injection molding to manufacture biodegradable films and molded pieces (Bengtsson et al., 2010).

Diffractograms for PHA produced with all bacterial strains studied and their degree of crystallinity $\left(I_{c}\right)$ are shown in Figure 3. It is possible to observe the

Table 3. Initial degradation $\left(\mathrm{T}_{\text {in }}\right)$ and maximum decomposition temperatures $\left(\mathrm{T}_{\text {maxdec }}\right)$, along with total weight loss of soybean seed and PHA produced by $C$. necator and B. cepacia strains.

\begin{tabular}{|c|c|c|c|c|c|}
\hline \multirow[b]{2}{*}{$\begin{array}{l}\text { Microorganism } \\
\text { strain }\end{array}$} & \multicolumn{2}{|c|}{ First event } & \multicolumn{2}{|c|}{ Second event } & \multirow{2}{*}{$\begin{array}{c}\text { Total } \\
\text { weight } \\
\text { loss (\%) }\end{array}$} \\
\hline & $\begin{array}{l}\mathbf{T}_{\text {in }} \\
\left({ }^{\circ} \mathrm{C}\right)\end{array}$ & $\begin{array}{c}\mathbf{T}_{\text {maxdec }} \\
\left({ }^{\circ} \mathrm{C}\right)\end{array}$ & $\begin{array}{c}\mathbf{T}_{\text {in }} \\
\left({ }^{\circ} \mathrm{C}\right)\end{array}$ & $\begin{array}{c}\mathbf{T}_{\text {maxdec }} \\
\left({ }^{\circ} \mathrm{C}\right)\end{array}$ & \\
\hline C. necator IPT 026 & 304.35 & 327.21 & 411.51 & 432.77 & 98.16 \\
\hline C. necator IPT 027 & 307.03 & 328.41 & 410.44 & 433.16 & 98.26 \\
\hline B. cepacia IPT 119 & 206.09 & 263.63 & 296.87 & 312.94 & 95.23 \\
\hline B. cepacia IPT 400 & 207.15 & 262.48 & 298.73 & 315.93 & 94.61 \\
\hline \multicolumn{6}{|c|}{$\begin{array}{r}\text { Soybean seed } \\
\end{array}$} \\
\hline First event & \multicolumn{2}{|c|}{ Second event } & \multicolumn{2}{|c|}{ Third event } & \multirow[b]{2}{*}{$\begin{array}{l}\text { Total weight } \\
\text { loss }(\%)\end{array}$} \\
\hline $\begin{array}{cc}\mathbf{T}_{\text {in }} & \mathbf{T}_{\text {maxde }} \\
\left({ }^{\circ} \mathrm{C}\right) & \left({ }^{\circ} \mathrm{C}\right)\end{array}$ & $\begin{array}{l}\mathbf{T}_{\text {in }} \\
\left({ }^{\circ} \mathrm{C}\right)\end{array}$ & $\begin{array}{c}\mathbf{T}_{\text {maxdec }} \\
\left({ }^{\circ} \mathrm{C}\right)\end{array}$ & $\begin{array}{c}\mathbf{T}_{\text {in }} \\
\left({ }^{\circ} \mathrm{C}\right)\end{array}$ & $\mathbf{T}_{\text {maxdec }}\left({ }^{\circ} \mathrm{C}\right)$ & \\
\hline 205.59 & 340.99 & 367.89 & 408.79 & 434.30 & $77.88 \%$ \\
\hline
\end{tabular}




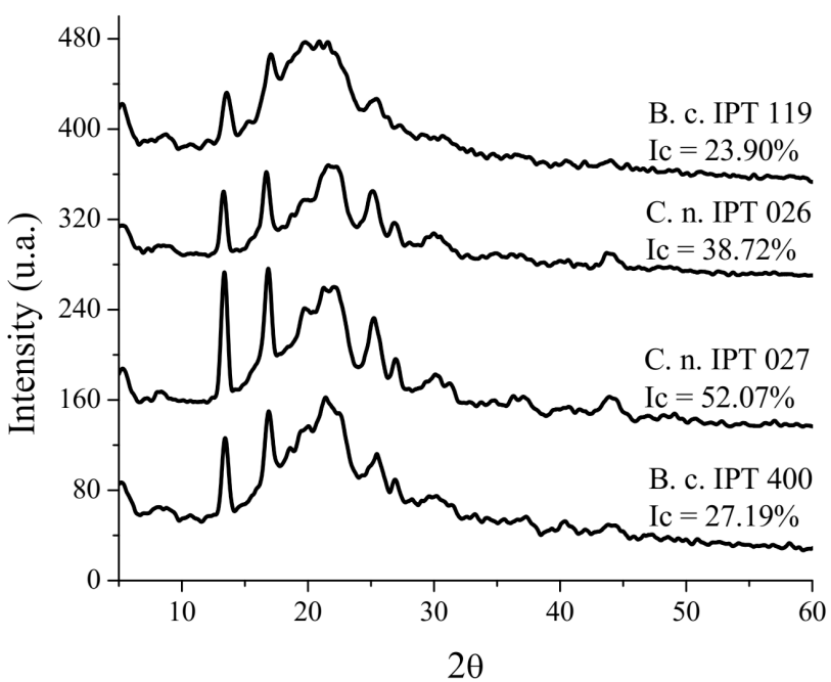

Figure 3. X-ray diffractograms of PHA produced by $C$. necator and B. cepacia strains in submerged cultivation with soybean.

diffraction peaks at $2 \theta$ for all samples evaluated, reflecting the atomic arrangement in their structure. There were discrete variations in the curves due to the different producer microorganisms. Even so, all PHA presented peaks at $13.34^{\circ}, 16.85^{\circ}, 21.70^{\circ}$ and $25.30^{\circ}$, which are typical of semi-crystalline polyesters (Barud et al., 2011).

Degree of crystallinity ( $\left.\mathrm{I}_{c}\right)$ is an important factor for mechanical performance and processability since it affects the molecular conformation and intermolecular packing of the atoms of the material. The $\mathrm{I}_{c}$ ideal value must not be much superior to $50 \%$, otherwise, problems related with brittleness and rigidity starts to emerge, making polymer processing more challenging and requiring corrective actions that can result in an operation price rise (Laycock et al., 2013; Rehm, 2010).

$\mathrm{I}_{\mathrm{c}}$ of the polymers studied ranged from $52.0 \%$ to $23.9 \%$, demonstrating that the microorganism strain had significant impact on the polyester structural arrangement. PHA produced from $C$. necator IPT 027 exhibited the highest $\mathrm{I}_{\mathrm{c}}$, showing the predominant crystalline structure of this biomaterial. In contrast, all other polyesters assessed exhibited a predominant amorphous structure, that can be comparatively detected by the intensity of the diffraction peaks in the $2 \theta$ range (Figure 3 ).

On average, the materials produced by $C$. necator strains displayed an $\mathrm{I}_{c}$ of $45.4 \%$, superior to $B$. cepacia, with an $I_{c}$ of $25.5 \%$, revealing that, in regard to this property, the last strains produced better polymers, which is associated with their specific bioconversion ability.

PHA degrees of crystallinity reported in the literature (Campos et al., 2014; Ribeiro et al., 2015; Ribeiro et al., 2016; Bengtsson et al., 2010) are highly dependable on the substrate and on the producer microorganism, with values ranging from $66.7 \%$ to $35.3 \%$. Comparatively, the polymers produced in this paper exhibited low crystallinity and great potential for industrial processing and applications based on their molecular arrangement.

Weight-average molecular mass (Mw), numberaverage molecular mass (Mn) and polydispersity (PDI) data, obtained from size-exclusion chromatography, are organized in Table 4 for the polymers produced from soybean. Figure 4 illustrates the biopolymer separation chromatograms. The calibration curve of standard polystyrene with different values of $\mathrm{Mw}$ as a function of column retention time $(\mathrm{t})$, used to calculate the samples Mw, and its coefficient of determination, are displayed in Eq (3).

$\log (\mathrm{Mw})=-0.8364 \mathrm{t}+14.831 \quad \mathrm{R}^{2}=0.9917$

The microorganisms that produced the highest weight-average molecular mass were $C$. necator, with an average $\mathrm{Mw}$ of $216.081 \mathrm{kDa}$, against an $\mathrm{Mw}$ average value of $124.323 \mathrm{kDa}$ observed for $B$. Cepacia strains, showing the impact of different synthesizer microorganisms on polymer size, even when offered the same substrate and growth conditions. These data are coherent with the literature, since PHA Mw has been reported to range between 50 and $3,000 \mathrm{kDa}$ depending on the biosynthesis conditions (Madison et al., 1999; Sudesh et al., 2000). PHA polydispersity, which measures the heterogeneity of polymer molecular sizes, shows that $C$. necator IPT 026 produced a material that is more homogenous, with a PDI of 1.81. In contrast, B. cepacia IPT 119 exhibited the highest dispersion in polymer size with a PDI of 2.83, what can be confirmed by Figure 4 . Yet, in his investigations with PHA production from wastewater sludge, Sang-Hyeop et al. (2016) reported values of PDI that extended to numbers as high as 3.44.

Table 4. Molar mass of PHA produced by the strains C. necator IPT 026 and IPT 027, and B. cepacia IPT 119 and IPT 400 from soybean.

\begin{tabular}{|c|c|c|c|c|c|}
\hline \multirow{2}{*}{ Microorganism } & \multicolumn{3}{|c|}{ Mw (kDa) } & \multirow{2}{*}{$\begin{array}{c}\text { Mn } \\
\text { (kDa) }\end{array}$} & \multirow{2}{*}{ PDI } \\
\hline & Minimum & Medium & Maximum & & \\
\hline C. necator IPT 026 & 4.624 & 240.868 & 2661.828 & 132.938 & 1.81 \\
\hline C. necator IPT 027 & 4.624 & 191.293 & 2195.533 & 77.968 & 2.45 \\
\hline B. cepacia IPT 119 & 9.430 & 130.287 & 977.804 & 45.907 & 2.83 \\
\hline B. cepacia IPT 400 & 4.199 & 118.359 & 888.038 & 47.604 & 2.49 \\
\hline
\end{tabular}




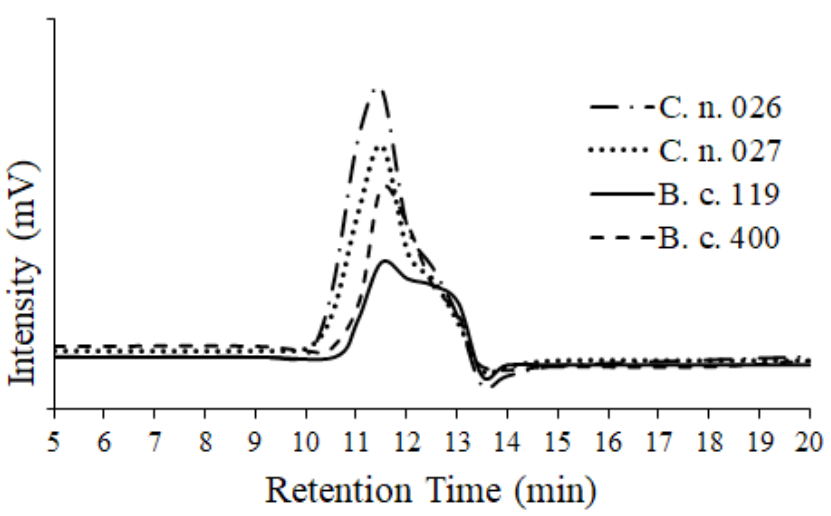

Figure 4. Chromatograms of PHAs produced by the C. necator, and B. cepacia strains from soybean.

Higher PDI values are often related to either chain transfer reactions or depolymerase activity during granule formation within the cells or to random decay of active synthase molecules, which is an undesirable phenomenon in the biosynthesis (Laycock et al., 2013).

\section{CONCLUSIONS}

All strains studied were able to use the offered substrate to synthetize PHA. Regarding production, C. necator strains exhibited the highest performance in polymer accumulation. These microorganisms also produced polyesters with the highest thermal stability and weight-average molecular masses. Polyesters synthesized by $B$. cepacia revealed predominant amorphous molecular arrangements with the lowest crystallinity. C. necator and B. cepacia influenced importantly PHA production and characteristics, confirming that the biocatalyst variable is of critical significance in the process. The relationship between PHA accumulation, cellular production and substrate protein content must be closely investigated in order to support more evidence and trigger higher PHA production. Lastly, medium composition and fermentation conditions can be optimized to maximize biopolymer production.

\section{NOMENCLATURE}

$\mathrm{A}_{\mathrm{FA}} \quad$ Area of fatty acid methyl ester peak in the chromatogram of the lipid fraction of soybean $\left(\mathrm{m}^{2}\right)$.

$\mathrm{A}_{\mathrm{IS}} \quad$ Area of internal standard fatty acid methyl ester peak in the chromatogram of the lipid fraction of soybean $\left(\mathrm{m}^{2}\right)$.

C Total carbon content on soybean $(\mathrm{g})$.

$\mathrm{C}_{\mathrm{TL}} \quad$ Percentage composition of total lipids from the sample $(\%)$.

F Correction factor of fatty acid methyl ester to fatty acid (Dimensionless).
$\mathrm{F}_{\mathrm{FA}} \quad$ Correction factor response of each fatty acid methyl ester ionization detector, relative to C23:0 (Dimensionless).

I $\quad$ Degree of crystallinity (Dimensionless).

M Lipid sample mass (mg).

$\mathrm{M}_{\mathrm{IS}} \quad$ Weight of the internal standard added to the soybean lipid sample (mg).

$\mathrm{Mn} \quad$ Number-average molecular mass $\left(\mathrm{g} \mathrm{mol}^{-1}\right)$.

$\mathrm{Mw} \quad$ Weight-average molecular mass $\left(\mathrm{g} \mathrm{mol}^{-1}\right)$.

$\mathrm{N} \quad$ Total carbon content on soybean (g).

PDI Polydispersity (Dimensionless).

$\mathrm{t} \quad$ Time (s).

$\mathrm{T}_{\text {in }} \quad$ Initial degradation temperature $\left({ }^{\circ} \mathrm{C}\right)$.

$\mathrm{T}_{\text {maxdec }}^{\text {in }}$ Maximum decomposition temperature $\left({ }^{\circ} \mathrm{C}\right)$.

\section{REFERENCES}

Altaee, N., Fahdil, A., Yousif, E. and Sudesh, K., Recovery and subsequent characterization of polyhydroxybutyrate from Rhodococcusequi cells grown on crude palm kernel oil. Journal of Taibah University for Science, 10, 543-550 (2016). https:// doi.org/10.1016/j.jtusci.2015.09.003

AOAC (Association of Official Analytical Chemists). Official Methods of Analysis of AOAC International. In: Horwitz, W., 16th edition. Gaithersburg, Maryland (1997).

Barud, H.S., Souza, J.L., Santos, D.B., Crespi, M.S., Ribeiro, C.A., Messaddeq, Y. and Ribeiro, S.J.L., Bacterial cellulose/poly(3-hydroxybutyrate) composite membranes. Carbohydrate Polymers, 83, 1279-1284 (2011). https://doi.org/10.1016/j. carbpol.2010.09.049

Bengtsson, S., Pisco, A.R., Johansson, P., Lemos, P.C. and Reis, M.A.M., Molecular weight and thermal properties of polyhydroxyalkanoates produced from fermented sugar molasses by open mixed cultures. Journal of Biotechnology, 147, 172-179 (2010). https://doi.org/10.1016/j.jbiotec.2010.03.022

Berto, D., Rampazzo, F., Gion, C., Noventa, S., Ronchi, F., Traldi, U., Giorgi, G., Cicero, A.M. and Giovanardi, O., Preliminary study to characterize plastic polymers using elemental analyser/isotope ratio mass spectrometry (EA/IRMS). Chemosphere, 176, 47-56 (2017). https://doi.org/10.1016/j. chemosphere.2017.02.090

Bligh, E.G. and Dyer, W.J., A rapid method of total lipid extraction and purification. Canadian Journal of Biochemistry and Physiology, 37, 911-917 (1959). https://doi.org/10.1139/o59-099

Campos, M.I., Figueiredo, T.V.B., Sousa, L.S. and Druzian, J.I., The influence of crude glycerin and nitrogen concentrations on the production of PHA by Cupriavidus necator using a response surface methodology and its characterizations. Industrial Crops and Products, 52, 338-346 (2014). https:// doi.org/10.1016/j.indcrop.2013.11.008 
Carvalho, G., Oehmen, A., Albuquerque, M.G.E. and Reis, M.A.M., The relationship between mixed microbial culture composition and PHA production performance from fermented molasses. New Biotechnology, 31, 257-263 (2014). https://doi. org/10.1016/j.nbt.2013.08.010

Chen, Z., Guo, Z., Wen, Q., Huang, L., Bakke, R. and $\mathrm{Du}, \mathrm{M}$., Modeling polyhydroxyalkanoate (PHA) production in a newly developed aerobic dynamic discharge (ADD) culture enrichment process. Chemical Engineering Journal, 298, 36-43 (2016). https://doi.org/10.1016/j.cej.2016.03.133

Dias, M.M.S., Koller, M., Puppi, D., Morelli, A., Chiellini, F. and Braunegg, G., Fed-batch synthesis of poly(3-hydroxybutyrate) and poly(3hydroxybutyrate-co-4-hydroxybutyrate) from sucrose and 4-hydroxybutyrate precursors by Burkholderia sacchari strain DSM 17165. Bioengineering, 4, 1-19 (2017).

Erickson, B., Nelson, J.E. and Winters, P., Perspective on opportunities in industrial biotechnology in renewable chemicals. Biotechnology Journal, 7, 176-185 (2012). https://doi.org/10.1002/ biot.201100069

Faccin, D.J.L., Rech, R., Secchi, A.R., Cardozo, N.S.M. and Ayub, M.A.Z., Influence of oxygen transfer rate on the accumulation of poly(3hydroxybutyrate) by Bacillus megaterium. Process Biochemistry,48, 420-425 (2013). https://doi. org/10.1016/j.procbio.2013.02.004

Felberg, I., Deliza, R., Gonçalves, E.B., Antoniassi, R., Freitas, S.C. and Cabral, L.C., Bebida mista de extrato de soja integral e castanha-do-brasil: caracterização físico- química, nutricional e aceita. Alimentos e Nutrição, 15, 163-174 (2004).

Figueiredo, P.N., New challenges for public research organizations in agricultural innovation in developing economies: Evidence from Embrapa in Brazil's soybean industry. The Quarterly Review of Economics and Finance, 62, 21-32 (2016). https:// doi.org/10.1016/j.qref.2016.07.011

Galão, O.F., Carrão-Panizzi, M.C., Mandarino, J.M.G., Júnior, O.O.S., Maruyama, S.A., Figueiredo, L.C., Bonafe, E.G. and Visentainer, J.V., Differences of fatty acid composition in Brazilian genetic and conventional soybeans (Glycine $\max$ (L.) Merrill) grown in different regions. Food Research International, 62, 589-594 (2014). https://doi. org/10.1016/j.foodres.2014.04.025

Genovese, M.I., Davila, J. and Lajolo, F.M., Isoflavones in Processed Soybean Products from Ecuador. Brazilian Archives of Biology and Technology, 49, 853-869 (2006). https://doi.org/10.1590/S151689132006000600020

González-García, Y., Meza, J.C.C., Reynoso, O.G. and López, J.A.C., Síntesis Y Biodegradación de Polihidroxialcanoatos: Plásticos de Origen
Microbiana. Revista internacional de contaminación ambiental, 29, 77-115 (2013).

Gowda, V. and Shivakumar, S., Agrowaste-based Polyhydroxyalkanoate (PHA) Production using Hydrolytic Potential of Bacillus thuringiensis IAM 12077. Brazilian Archives of Biology and Technology, 57, 55-61 (2014). https://doi. org/10.1590/S1516-89132014000100009

Hartman, G.L., West, E.D. and Herman, T.K., Crops that feed the world 2 - Soybean worldwide production, use, and constraints caused by pathogens and pests. Food Security, 3, 5-17 (2011). https://doi.org/10.1007/s12571-010-0108-x

He, W.N., Zhang, Z.M., Hu, P. and Chen, G. Q., Microbial synthesis and characterization of polyhydroxyalkanoates by strain DG17 from glucose.Acta Polymerica Sinica, 6, 709-714 (1999).

Hong, K., Sun, S., Tian, W., Chen, G.Q. and Huang, W., A rapid method for detecting bacterial polyhydroxyalkanoates in intact cells by Fourier transform infrared spectroscopy. Applied Microbiology and Biotechnology, 51, 523-526 (1999). https://doi.org/10.1007/s002530051427

Joseph, J.D. and Ackman, R.G., Capillary column gas chromatographic method for analysis of encapsulated fish oils and fish oil ethyl esters: collaborative study. Journal of AOAC International, 75, 488-506 (1992).

Koller, M., Maršálekc, L., Dias, M.M.S. and Braunegg, G., Producing microbial polyhydroxyalkanoate (PHA) biopolyesters in a sustainable manner. New Biotechnology, 37, 24-38 (2017). https://doi. org/10.1016/j.nbt.2016.05.001

Kourmentza, C., Plácido, J., Venetsaneas, N., Burniol-Figols, A., Varrone, C., Gavala, H.N. and Reis, M.A.M., Recent Advances and Challenges towards Sustainable Polyhydroxyalkanoate (PHA) Production. Bioengineering, 4, 1-43 (2017). https:// doi.org/10.3390/bioengineering4020055

Kumar, M.S., Mudliar, S.N., Reddy, K.M.K. and Chakrabarti, T., Production of biodegradable plastics from activated sludge generated from a food processing industrial wastewater treatment plant. Bioresource Technology, 95, 327-330 (2004). https://doi.org/10.1016/j.biortech.2004.02.019

Laycock, B., Halley, P., Pratt, S.,Werker, A. and Lant, P., The chemomechanical properties of microbial polyhydroxyalkanoates. Progress In Polymer Science, 38, 536-583 (2013). https://doi. org/10.1016/j.progpolymsci.2012.06.003

Liu, S., Bioprocess Engineering: Kinetics, Sustainability, and Reactor Design. 2nd Edition. Elsevier, New York (2017).

Madison, L.L. and Huisman, G.W., Metabolic Engineering of Poly(3-Hydroxyalkanoates): From DNA to Plastic. Microbiology and Molecular Biology Reviews, 63, 21-53 (1999). 
Morais, C., Freitas, F., Cruz, M.V., Paiva, A., Dionísio, M. and Reis, M.A.M., Conversion of fat-containing waste from the margarine manufacturing process into bacterial polyhydroxyalkanoates. International Journal of Biological Macromolecules, 71, 68-73 (2014). https://doi.org/10.1016/j. ijbiomac.2014.04.044

Muhr, A., Rechberger, E.M., Salerno, A., Reiterer, A., Malli, K., Strohmeier, K., Schober, S., Mittelbach, M. and Koller, M., Novel description of mcl-PHA biosynthesis by Pseudomonas chlororaphis from animal-derived waste. Journal of Biotechnology, 165, 45-51 (2013a). https://doi.org/10.1016/j. jbiotec.2013.02.003

Muhr, A., Rechberger, E.M., Salerno, A., Reiterer, A., Schiller, M., Kwiecień, M., Adamus, G., Kowalczuk, M., Strohmeier, K., Schober, S., Mittelbach, M. and Koller, M., Biodegradable latexes from animal-derived waste: Biosynthesis and characterization of mcl-PHA accumulated by Ps. citronellolis. Reactive and Functional Polymers, 73, 1391-1398 (2013b). https://doi.org/10.1016/j. reactfunctpolym.2012.12.009

Nascimento, I.A., Marques, S.S.I., Cabanelas, I.T.D., Pereira, S.A. and Druzian, J.I., Screening microalgae strains for biodiesel production: lipid productivity and estimation of fuel quality based on fatty acids profiles as selective criteria. Bioenergy Resource, 6, 1-13 (2013). https://doi.org/10.1007/ s12155-012-9222-2

Nelson, D.W. and Sommers, L.E., Total carbon, organic carbon, and organic matter. In: Page, A.L., Miller, R.H and Keeney, D.R., Methods of soil analysis. Part 2. Chemical and microbiological properties. Agronomy monograph 9, American Society of Agronomy, Madison (1982).

Nonato, R.V., Mantelatto, P.E. and Rossell, C.E., Integrated production of biodegradable plastic, sugar and ethanol. Applied Microbiology Biotechnology, 57, 1-5 (2001). https://doi. org/10.1007/s002530100732

Nwokola, E. Soybean (Glycine max (L.) Merr.). In: Nwokola, E. and Smartt, J., Food and Feed Legumes and Oilseeds. 1st Edition. Chapman \& Hall, London (1996). https://doi.org/10.1007/9781-4613-0433-3 8

Oliveira, C.S.S., Silva, C.E., Carvalho, Gilda, R. and Maria, A., Strategies for efficiently selecting PHA producing mixed microbial cultures using complex feedstocks: feast and famine regime and uncoupled carbon and nitrogen availabilities. New Biotechnology, 37, 69-79 (2017). https://doi. org/10.1016/j.nbt.2016.10.008

Pal, A., Prabhu, A., Kumar, A.A., Rajagopal, B., Dadhe, K., Ponnamma, V. and Shivakumar, S., Optimization of process parameters for maximum poly(-beta-)hydroxybutyrate (PHB) production by Bacillus thuringiensis IAM 12077. Polish Journal of Microbiology, 58, 149-154 (2009).

Ramadas, N.V., Singh, K.S., Soccol, R.C. and Pandey, A., Polyhydroxybutyrate production using agroindustrial residue as substrate by Bacillus sphaericus NCIM 5149. Brazilian Archives of Biology and Technology, 52, 17-23 (2009). https:// doi.org/10.1590/S1516-89132009000100003

Ray, S., Prajapati, V., Patel, K. and Trivedi, U., Optimization and characterization of PHA from isolate Pannonibacter phragmitetus ERC8 using glycerol waste. International Journal of Biological Macromolecules, 86, 741-749 (2016). https://doi. org/10.1016/j.ijbiomac.2016.02.002

Rehm, B.H.A., Bacterial polymers: biosynthesis, modifications and applications. Nature Reviews Microbiology, 8, 578-592 (2010). https://doi. org/10.1038/nrmicro2354

Ribeiro, P.L.L., Silva, A.C.M.S., Filho, J.A.M. and Druzian, J.I., Impact of different by-products from the biodiesel industry and bacterial strains on the production, composition, and properties of novel polyhydroxyalkanoates containing achiral building blocks. Industrial Crops and Products, 69, 212-223 (2015). https://doi.org/10.1016/j. indcrop.2015.02.035

Ribeiro, P.L.L., Silva, G.S. and Druzian, J.I., Evaluation of the Effects Of Crude Glycerol on the Production and Properties of Novel Polyhydroxyalkanoate Copolymers Containing High 11-Hydroxyoctadecanoate by Cupriavidus necator IPT 029 and Bacillus Megaterium IPT 429. Polymers for Advanced Technologies, 27, 542-549 (2016). https://doi.org/10.1002/pat.3725

Riedel, S.L., Jahns, S., Koenig, S., Bock, M.C.E., Brigham, C.J., Bader, J. and Stahl, U., Polyhydroxyalkanoates production with Ralstonia eutropha from low quality waste animal fats. Journal of Biotechnology, 214, 119-127 (2015). https://doi.org/10.1016/j.jbiotec.2015.09.002

Sang-Hyeop, C., Jae-Hyop, S., Yousuf, J.,Mohd, Z. and Hung-Suck, P., Characterization of polyhydroxyalkanoates extracted from wastewater sludge under different environmental conditions. Biochemical Engineering Journal, 112, 1-12 (2016). https://doi.org/10.1016/j.bej.2015.12.021

Shahzad, K., Narodoslawsky, M., Sagir, M., Ali, N., Ali, S., Rashid, M.I., Ismail, I.M.I. and Koller, M., Techno-economic feasibility of waste biorefinery: Using slaughtering waste streams as starting material for biopolyester production. Waste Management, 67, 73-85 (2017). https://doi. org/10.1016/j.wasman.2017.05.047

Silva, L.H., Costa, P.F.P., Nomiyama, G.W., Souza, I.P. and Chang, Y.K., Physicochemical and technological characterization of whole soybean flour fermented 
by Aspergillus oryzae. Brazilian Journal of Food Technology, 15, 300-306 (2012). https://doi. org/10.1590/S1981-67232012005000025

Srivastava, S.K. and Tripathi, A.D., Effect of saturated and unsaturated fatty acid supplementation on bioplastic production under submerged fermentation. 3 Biotech, 3, 389-397 (2013).

Sudesh, K., Abe, H. and Doi, Y., Synthesis, structure and properties of polyhydroxyalkanoates: biological polyesters. Progress in Polymer Science, 25, 1503-1555 (2000). https://doi.org/10.1016/ S0079-6700(00)00035-6

Wang, B., Sharma-Shivappa, R.R., Olson, J.W. and Khan, S. A. Production of polyhydroxybutyrate (PHB) by Alcaligeneslatus using sugarbeet juice. Industrial Crops and Products, 43, 802-811 (2013). https://doi.org/10.1016/j.indcrop.2012.08.011

Wu, Q., Sun, S.Q., Yu, P.H.F., Chen, A.X.Z. and Chen, G.Q., Environmental dependence of microbial synthesis of polyhydroxyalkanoates. Acta Polymerica Sinica, 6, 751-756 (2000).

Vonk, C.G., Computerization of Ruland's X-ray method for determination of the crystallinity in polymers. Journal of Applied Crystallography, 6, 148-152 (1973). https://doi.org/10.1107/ S0021889873008332

Xu, J., Guo, B.H., Yang, R., Wu, Q., Chen, G.Q. and Zhang, Z.M., In situ FTIR study on melting and crystallization of polyhydroxyalkanoates, Polymer, 43, 6893-6899 (2002). https://doi.org/10.1016/ S0032-3861(02)00615-8

Zhu, X. and Yan, D., In situ FTIR spectroscopy study on the melting process of isotactic poly(propylene). Macromolecular Chemistry and Physics, 202, 1109-1113 (2001). https://doi.org/10.1002/1521$3935(20010401) 202: 7 \% 3$ C 1109 : :A ID MACP1109\%3E3.0.CO;2-1 
